\title{
Managing Local Stressors for Coral Reef Condition and Ecosystem Services Delivery Under Climate Scenarios
}

Mariska Weijerman ${ }^{1,2 *}$, Lindsay Veazey ${ }^{3}$, Susan Yee $^{4}$, Kellie Vaché ${ }^{5}$, Jade M. S. Delevaux ${ }^{3}$, Mary K. Donovan ${ }^{6}$, Kim Falinski ${ }^{3}$, Joey Lecky ${ }^{1,3}$ and Kirsten L. L. Oleson ${ }^{1,3}$

\begin{abstract}
${ }^{1}$ Joint Institute of Marine and Atmospheric Research, University of Hawaili at Mānoa, Honolulu, HI, United States, ${ }^{2}$ Pacific Islands Fisheries Science Center, National Oceanic and Atmospheric Administration, Honolulu, HI, United States, ${ }^{3}$ Department of Natural Resources and Environmental Management, University of Hawai'i at Mānoa, Honolulu, HI, United States, ${ }^{4}$ Gulf Ecology Division, U.S. Environmental Protection Agency, Gulf Breeze, FL, United States, ${ }^{5}$ Biological and Ecological Engineering, Oregon State University, Corvallis, OR, United States, ${ }^{6}$ Hawai'i Institute of Marine Biology, University of Hawai'i at Mānoa, Kānéohe, HI, United States
\end{abstract}

\section{OPEN ACCESS}

Edited by:

Jamie C. Tam

Bedford Institute of Oceanography,

Canada

Reviewed by:

Jeremy Baron Pittman,

University of Waterloo, Canada

Blair Greenan,

Department of Fisheries and Oceans

(Canada), Canada

${ }^{*}$ Correspondence:

Mariska Weijerman

mariska.weijerman@noaa.gov

Specialty section:

This article was submitted to Global Change and the Future Ocean,

a section of the journal

Frontiers in Marine Science

Received: 07 August 2018

Accepted: 23 October 2018

Published: 09 November 2018

Citation:

Weijerman $M$, Veazey L, Yee $S$,

Vaché $K$, Delevaux JMS,

Donovan MK, Falinski K, Lecky J and

Oleson KLL (2018) Managing Local

Stressors for Coral Reef Condition and

Ecosystem Services Delivery Under

Climate Scenarios.

Front. Mar. Sci. 5:425.

doi: 10.3389/fmars.2018.00425
Coral reefs provide numerous ecosystem goods and services, but are threatened by multiple environmental and anthropogenic stressors. To identify management scenarios that will reverse or mitigate ecosystem degradation, managers can benefit from tools that can quantify projected changes in ecosystem services due to alternative management options. We used a spatially-explicit biophysical ecosystem model to evaluate socio-ecological trade-offs of land-based vs. marine-based management scenarios, and local-scale vs. global-scale stressors and their cumulative impacts. To increase the relevance of understanding ecological change for the public and decision-makers, we used four ecological production functions to translate the model outputs into the ecosystem services: "State of the Reef," "Trophic Integrity," "Fisheries Production," and "Fisheries Landings." For a case study of Maui Nui, Hawai' i, land-based management attenuated coral cover decline whereas fisheries management promoted higher total fish biomass. Placement of no-take marine protected areas (MPAs) across $30 \%$ of coral reef areas led to a reversal of the historical decline in predatory fish biomass, although this outcome depended on the spatial arrangement of MPAs. Coral cover declined less severely under strict sediment mitigation scenarios. However, the benefits of these local management scenarios were largely lost when accounting for climate-related impacts. Climate-related stressors indirectly increased herbivore biomass due to the shift from corals to algae and, hence, greater food availability. The two ecosystem services related to fish biomass increased under climate-related stressors but "Trophic Integrity" of the reef declined, indicating a less resilient reef. "State of the Reef" improved most and "Trophic Integrity" declined least under an optimistic global warming scenario and strict local management. This work provides insight into the relative influence of land-based vs. marine-based management and local vs. global stressors as drivers of changes in ecosystem dynamics while quantifying the tradeoffs between conservation- and extraction-oriented ecosystem services.

Keywords: trade-off, ecosystem-based management, multiple stressors, future scenarios, coral reefs, biophysical model, Hawai'i 


\section{INTRODUCTION}

Coral reef ecosystems provide valuable resources. They buffer coastal erosion, provide a cornucopia of food resources, attract tourism dollars, supply construction and pharmaceutical materials, and provide recreational opportunities for humans and essential habitat for threatened and endemic organisms (HoeghGuldberg, 1999; Moberg and Folke, 1999; Spalding et al., 2017). Furthermore, nature-based solutions, such as using living reefs as natural barriers for storm protection, are more cost-effective than manufactured infrastructure (Daily and Matson, 2008).

Despite the importance of reef ecosystems, they are under threat on a local scale from coastal development, overfishing, invasive species, and pollution, and on a global scale from ocean acidification, warming, and hypoxia (Carlton and Scanlon, 1985; Jokiel and Coles, 1990; Pörtner et al., 2005; Hoegh-Guldberg et al., 2011; Prouty et al., 2014). Two extensive reviews on threats to coral reefs identified ocean warming and ocean acidification as prominent threats (Burke et al., 2011; Brainard et al., 2013). Increasing carbon dioxide $\left(\mathrm{CO}_{2}\right)$ emissions are slowly causing the world's oceans to become warmer and more acidic. Ocean acidification reduces calcification rates of all calcifying organisms including corals. Intense or prolonged ocean warming can result in the expulsion of the symbiotic algae that live in the coral tissue leaving them looking "bleached" and is hence called coral bleaching. Bleached corals have a higher change of mortality as they become more susceptible to pathogens (Maynard et al., 2015b). These threats are projected to intensify in coming decades (Van Hooidonk et al., 2013; Maynard et al., 2015b). Chronic stressors can lead to a more degraded reef system that has tipped to an algal dominated benthos (Bellwood et al., 2004; Hughes et al., 2010), and a replacement of top predatory fishes (large slow growing fishes) with species with a high turnover (Heithaus et al., 2008; Ruttenberg et al., 2011; Maynard et al., 2015a). These shifts are a concern because ecological functions and economic values diminish on such reef systems. Effective, long-term conservation of coral reefs and the goods and services they provide requires addressing the most critical threats.

The development of policies to address threats and promote ecosystem services is dependent on an understanding of ecosystem dynamics and responses to major stressors. Ecosystem models can synthesize the present-day condition and project changes of a system as a result of management regulations, climate conditions, or human use. Spatially explicit ecosystem models can also quantify the relative impacts of land-based vs. marine-based threats (e.g., land-based pollutants vs. fishing; (Álvarez-Romero et al., 2011; Barbier et al., 2011) and local vs. global stressors (Gurney et al., 2013; Weijerman et al., 2015). These types of models can evaluate tradeoffs of alternative courses of action to mitigate threats (Hulme, 2005; Fung, 2009; Weijerman et al., 2016). More recently, ecosystem models have been coupled with economic concepts to translate ecological outcomes in terms of human wellbeing, such as ecosystem services (Orlando and Yee, 2017).

One such spatially-explicit, biophysical ecosystem model is the COral Reef Scenario Evaluation Tool, CORSET (Fung, 2009; Melbourne-Thomas et al., 2011a; Principe et al., 2012).
It includes hydrodynamics (which defines the connectivity), ecological dynamics, and land-based (nutrient and sediment pollution) and marine-based (fishing) stressors as well as global climate-related stressors (hurricanes and ocean warming). Its main use is to evaluate tradeoffs of alternative management or climate-related scenarios (Melbourne-Thomas et al., 2011b). Building on the extensive work to estimate nutrient and sediment loads and fish extraction on a $500 \times 500 \mathrm{~m}$ scale around the main Hawaiian Islands (Wedding et al., 2017), we were able to incorporate these local stressors into the adapted CORSET model, the Hawai'i Reef dynamics Simulator or HIReefSim. Additionally, annual bleaching events were projected to start between 2035 and 2045 for the main Hawaiian Islands (Van Hooidonk et al., 2016). These projections were based on the results of an ensemble model of Intergovernmental Panel on Climate Change, Coupled Model Intercomparison Project Phase 5 (CMIP5), and as such, incorporated spatial variability in the effects of ocean warming on coral reefs. We used the projection of the Representative Concentration Pathway (RCP) 8.5 which estimates that by $2040 \mathrm{CO}_{2}$ emissions have reached $480 \mathrm{ppm}$ and the onset of annual bleaching has begun (Van Hooidonk et al., 2016).

While ecological indicators are being used explicitly in management and policy (Arkema et al., 2006; Levin et al., 2013), decision-makers and the public often relate more to direct experiences, such as fishing, recreation, or coastal protection (Yee et al., 2014). Goods and services provided by coral reef ecosystems have long been acknowledged (e.g., Moberg and Folke, 1999), however, the relatively recent field of ecosystem service modeling quantifies these direct benefits to humans from functioning ecosystems (Bagstad et al., 2013). One approach uses "ecological production functions" (EPFs) to translate environmental shifts into economic implications in a way that is meaningful to decision-makers and resource managers (Nelson et al., 2009; Orlando and Yee, 2017). EPFs calculate the provision of goods and services as a function of specific ecological attributes (de Groot et al., 2002). Defining an EPF relies on an ecological understanding of which attributes are important to ecological function, as well as an economic understanding of what functions are valuable to humans. While an EPF quantifies the potential supply of ecosystem goods and services based on ecosystem condition, the realized value will depend on human demand and access (Wainger and Boyd, 2009). Economic valuation requires another relationship, ecosystem service valuation functions, to derive the value society gets from direct (e.g., food and recreation) and indirect (e.g., shoreline protection) use and nonuse (e.g., existence) of these goods and services (Compton et al., 2011; Yee et al., 2014). In this way, EPFs can be used to evaluate changes in potential provision of goods and services due to management, climate, and human use that affect the ecosystem, while valuation functions can calculate the cost/benefit of those changes.

To evaluate how different local management approaches [sediment mitigation and marine protected areas (MPA) establishment] could improve the provision of coral reef ecosystem goods and services, an ecosystem model that simulates impacts of both land- and marine-based management was 
parameterized for Maui Nui, Hawai'i, i.e., the islands of Maui, Lāna'i, Moloka'i, and Kaho'olawe. These management approaches were also combined with two future severities of climate-related stressors. Reefs of Maui Nui served as a case study, but this tool can be used in other areas with similar local and global threats (Melbourne-Thomas et al., 2011a; Kapur and Franklin, 2017). Although several studies have shown the mitigating effects of local management on coral degradation in the face of climate change (Hughes et al., 2007; Kennedy et al., 2013; McClanahan et al., 2014), other studies have shown that under a "business as usual" greenhouse gas emissions future (IPCC RCP8.5 trajectory), local management may be unable to prevent further degradation of coral reef ecosystems (Thompson and Dolman, 2010; Selig et al., 2012; Weijerman et al., 2015; Hughes et al., 2017).

Here, we ask two questions: (1) What is the relative importance of land- and marine-based management action? and (2) Can local management mitigate the effects of climaterelated stressors? We expect that a combination of proactive local actions (sediment mitigation and fisheries controls) will attenuate declines in coral reef ecosystem goods and services delivery, but without local management, reefs will continue to decline, a trend exacerbated with more extreme future climate conditions.

\section{METHODS}

\section{Study Region}

Our study area encompasses $\sim 325 \mathrm{~km}^{2}$ of shallow coral reef habitat across the Hawaiian Islands of Maui, Molokai and Lāna'i, i.e., Maui Nui (Figure 1; the island of Kaho'olawe is excluded from this analysis due to lack of data). Of this area, $12 \mathrm{~km}^{2}(3.6 \%$ of total reef area) are classified as MPAs, with just over $9 \mathrm{~km}^{2}$ of the protected areas being designated as "no-take" area. The model domain consists of the shallow $(0-30 \mathrm{~m})$ reef zone around Maui Nui and is spatially represented by a $500 \times 500 \mathrm{~m}$ grid cell network.

\section{HIReefSim}

HIReefSim (Hawai'i Reef dynamics Simulator) is based on the framework of the Coral Reef Scenario Evaluation Tool (CORSET) developed by Fung (Fung, 2009) and adapted by Melbourne-Thomas et al. (2011a) and Principe et al. (2012). Model components include (1) $500 \times 500 \mathrm{~m}$ gridded basemaps of the study region (see details below); (2) model dynamics (see details below); (3) larval connectivity zone delineations, which detail transition probabilities between larval sources and sinks; and (4) hurricane zone delineations, which were designed to represent grouped swaths of coastline that are similarly affected by storm events. Modeled stressors include land-based sediment and nutrient input, fishing, hurricane damage to corals and macroalgae, and climate-related coral mortalities due to coral bleaching.

\section{Basemaps}

The HIReefSim model defines two consumer functional species groups, herbivorous (algal grazers) and piscivorous (predatory) fishes, and five benthic functional groups: macroalgae, turf algae, crustose-coralline algae (CCA), and spawner and brooder corals. Boosted regression trees generated spatial predictive maps of these ecological variables based on observations from a compilation of underwater surveys and an extensive gridded predictor dataset (Table S1) (Stamoulis et al., 2016; Delevaux, 2017). Unlike in the instantiation of CORSET, urchins and large $(>60 \mathrm{~cm})$ piscivores were not included due to very low abundance of large piscivores and a lack of urchin data preventing the creation of predictive maps.

\section{Dynamics}

Coral reef ecosystems are extremely complex systems and influenced by a myriad of variables. HIReefSim only includes key ecological dynamics by using differential equations to estimate the interactions among the functional groups and their response to stressors in each grid cell (Supplementary Text S2). For example, ocean warming has led to global degradation of coral reefs with a consequent loss of structure followed by a decrease in fish biomass (Alvarez-Filip et al., 2009; Graham and Nash, 2013). Additionally, on a local scale, an increase in nutrients leads to an increase in the faster-growing macroalgae which in turn can reduce the growth of corals and impede coral recruitment. These are the key dynamics that are incorporated in the model (Figure 2), other stressors to coral reef ecosystems (e.g., ocean acidification, hypoxia, invasive species) are not included. Fung (2009) and Melbourne-Thomas et al. (2011a) give detailed descriptions of the model development, general model behavior, and sensitivity analyses. Kapur and Franklin (2017) describe the applicability of the CORSET model for Hawaiian reef systems. Here, only the main components of CORSET that form the basis for HIReefSim input are described (Supplementary Text S2 has details of model equations and parameter estimates). Estimates of ecological variables represent the current ( 2004-2012) reef condition. The model has some stochasticity as it randomly selects the intensity, frequency, and region of impact to capture year-to-year variation in storms. The larval connectivity matrices were based on a pelagic duration of 45 days, calculated at the $50 \mathrm{~m}$ depth layer, for both corals and fishes (Wren and Kobayashi, 2016).

\section{Modeled Stressors}

Spatially explicit stressor functions included nutrification and sedimentation (changes modeled via parameter scaling), fishing (modeled as a spatial explicit reduction in fish biomass), and coral and macroalgal mortality resulting from wave action (severity dependent on hurricane zone; Figure 2; Table 1). The projected increase in bleaching-related coral mortalities was a non-spatial stressor, affecting all corals equally.

\section{Model Adaptations}

A regional study using CORSET (Kapur and Franklin, 2017), concluded a seemingly sustainable herbivore fishery would be possible despite the projected decline in coral cover. However, a limitation of this simplified model is its broad groupings of fishes in just herbivores and piscivores and the lack of twoway dynamics in fish size and fishing effort. For example, model results show that herbivores increase but the composition 


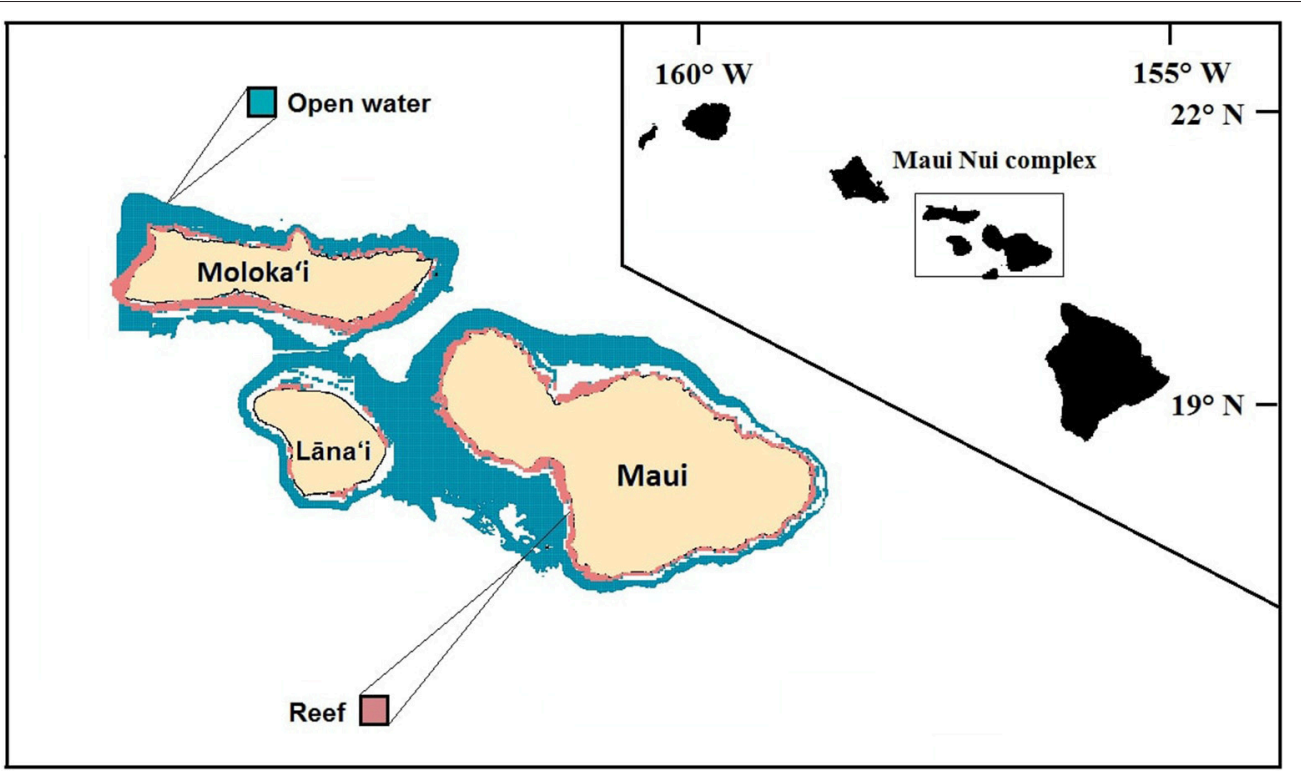

FIGURE 1 | Modeled area of the Maui Nui complex consisting of the Hawaiian Islands: Maui, Moloka'i, and Lāna'i, with the inset figure showing the location of Maui Nui in the Hawaiian Archipelago. The pink "reef" area is the 0-30 m depth range included in the model. The outer edge of open water area (blue) is defined by the $200 \mathrm{~m}$ depth contour. White areas interior of this indicate gaps in bathymetry data.

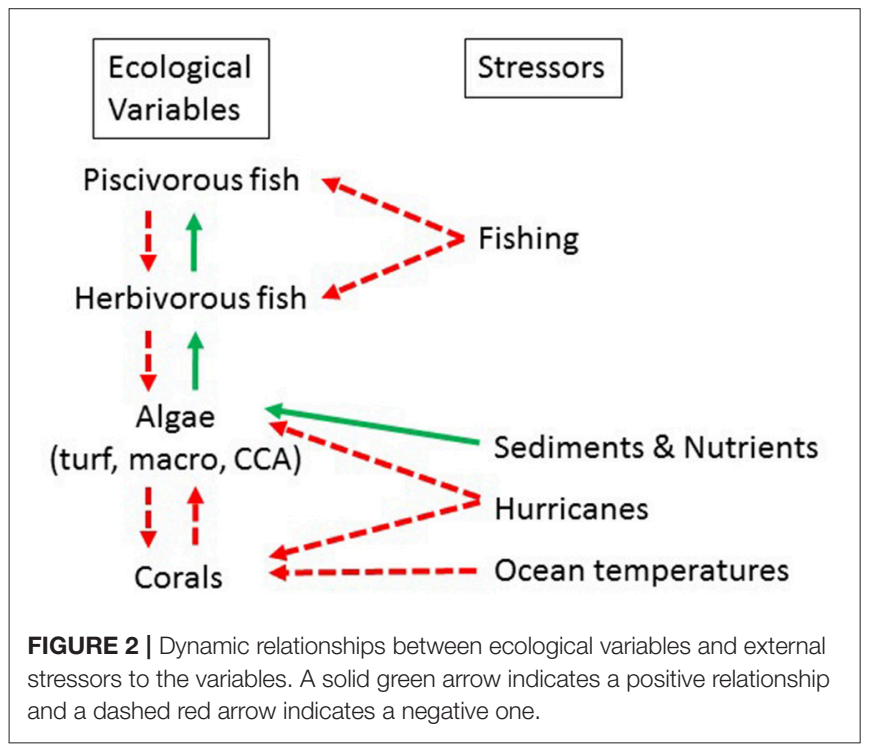

of this group is likely dominated by large-bodied herbivores, such as the larger surgeonfishes (e.g., Acanthurus dussiemeri, A. xanthopterus), that escape piscivore predation because of their size. However, if fishing is not restricted, these largerbodied fishes are key targets for spearfishers and an increase in spearfishing is not accounted for in the model. Additionally, reef structure is likely to erode due to coral cover decline, preventing fish recruits and juveniles from hiding (AlvarezFilip et al., 2009; DeMartini et al., 2010; Graham and Nash, 2013) and increasing their accessibility to their predatory fishes
(Rogers et al., 2014), ultimately leading to a decline in reef fish productivity (Gratwicke et al., 2005). Therefore, we included two scalars related to the structural complexity a coral reef provides for: (1) the survival of both herbivorous and piscivorous fish recruits given by the relationship survival $($ Frec $)=a C /[1+$ $\left.(a / b){ }^{*} C^{d}\right]$, where $C$ is coral cover, and $a, b$ and $d$ are fitted parameters (Table S2 in Supplementary Text S2; Gurney et al., 2013) and (2) the susceptibility of small and juvenile herbivorous fishes to predation with high coral cover leading to more hiding spaces and hence lower susceptibility to predation with the relationship refuge $\left.=\min \left(H, F_{\text {pred }}{ }^{*} C\right)\right]$, where $C$ is coral cover and $H$ herbivore biomass and $F_{\text {pred }}$ a fitted parameter (Table S2 in Supplementary Text S2) (Liu and Xing, 2012; Rogers et al., 2014).

\section{Model Calibration and Validation}

The model was validated using a two-fold approach (MelbourneThomas et al., 2011a,b):

- Calibrate model parameters to reproduce a community structure typical of stable, "healthy" Hawaiian reef in the absence of external stressors over long-term trajectories (40 years); and

- Evaluate whether the model can reproduce historic broadscale dynamics for the Maui Nui region over the past 30 years (1985-2015), given a timeline of known stressors (Supplementary Text S3). Historic land-based stressors (derived from land use maps in 1920) were scaled to present-day values (Supplementary Text S3).

Results of model validation are presented in Supplementary Text S3. During calibration, it became apparent 
TABLE 1 | Spatially-explicit stressors used to force scenario simulations in HIReefSim.

\begin{tabular}{|c|c|c|}
\hline Variable & Variable description & Source \\
\hline Fishing pressure $\left(\mathrm{kg} / \mathrm{km}^{2} / \mathrm{yr}\right)$ & $\begin{array}{l}\text { Annual average catch of reef fish (commercial, non-commercial shore-based, } \\
\text { and non-commercial boat-based) per cell from past } 10 \text { years of records. }\end{array}$ & (Wedding et al., 2017) \\
\hline Sediment input $\left(\mathrm{kg} / \mathrm{km}^{2} / \mathrm{yr}\right)$ & Sediment plumes originating from stream mouths and coastal pour points. & $\begin{array}{l}\text { (Wedding et al., 2017) } \\
\text { (Supplementary Text S3) }\end{array}$ \\
\hline Nutrient input $\left(\mathrm{kg} / \mathrm{km}^{2} / \mathrm{yr}\right)$ & $\begin{array}{l}\text { Nitrogen flux from onsite waste disposal systems (i.e., cesspools and septic } \\
\text { tanks) and fertilizers. }\end{array}$ & $\begin{array}{l}\text { (Wedding et al., 2017), Land use maps from } \\
1920 \text { \& } 2010 \text { (Supplementary Text S3) }\end{array}$ \\
\hline Hurricane zones & $\begin{array}{l}8 \text { regions uniquely impacted by northwestern winter swells and tsunami waves } \\
\text { from the southeast. }\end{array}$ & $\begin{array}{l}\text { Dr. Bill Ward, NOAA National Weather Service, } \\
\text { Pacific Region Headquarters }\end{array}$ \\
\hline
\end{tabular}

that the model was very sensitive to the parameters related to fish growth. For herbivores this was grazing pressure $(\mathrm{gt}, \mathrm{gm})$ and the biomass accumulation from grazing $(m m, m t, m e)$, and for piscivores this was prey availability (iph), predation pressure $(g p)$ and biomass accumulation from predation $(r p)$. We therefore randomly selected 50 values between the estimated ranges (Table S2) and assumed a normal distribution and ran each scenario 50 times to obtain uncertainty estimates related to these parameters.

\section{Scenario Simulations}

Fifteen scenarios of separate and coupled effects of climaterelated stressors and management actions were simulated (Table 2). To define values for future baseline stressors (sediment and nutrient influx, herbivore and piscivore catches), annual projected population growth of $0.8 \%$ was used (DBEDT, 2016). Fishing pressure, along with sediment and nutrient runoff, was assumed to increase proportionally with the projected population growth. These stressors were further adjusted as specified within the scenario (Table 2).

To simulate climate change, we focused on hurricanes and bleaching-related coral mortality events. Both the frequency and intensity of cyclones in the North Pacific have increased, and sea surface temperatures (SST), which are directly correlated with storm intensity, are increasing as well (Emanuel, 2005). Murakami et al. (2013) project an average $267 \%$ increase in the number of cyclones that will reach the main Hawaiian Islands between 2075 and 2099 ( 0.75 annually increasing to 2 annually). To reflect these projections, we included hurricane events which directly impact Maui Nui an average of every 10 years for the running period of the climate change scenarios (Table 2). We specified that each hurricane event would reduce coral and macroalgae cover by $49 \%$ based on the average observed reduction in living bottom cover across the west coast of Hawai' $i$ island (Dollar and Tribble, 1993). With the projected increase in sea surface temperatures, bleaching events will likely become annual, seasonal occurrences in the next 15-25 years (Van Hooidonk et al., 2016). Taking into consideration the variability in these estimates (Peters et al., 2017), we modeled a "severe" climate-related stressor scenario where we assumed that annual bleaching is every other year and a "less severe" climate-related stressor scenario where we assumed two annual bleaching events per decade.

\section{Ecological Production Functions (EPFs)}

We applied four Ecological Production Functions (EPFs): "State of the Reef” (unitless), "Trophic Integrity of the Reef” (unitless), "Fisheries Production" (i.e., resource fish biomass in $\mathrm{kg} / \mathrm{km}^{2}$ ), and "Fisheries Landings" (i.e., annual fish catch in $\mathrm{kg} / \mathrm{km}^{2}$ ) to translate HIReefSim model output into values important for management applications (Principe et al., 2012; Yee et al., 2014). These EPFs represent a supporting service (first two EPFs), a potential provisioning service, and an actual provisioning service (Millennium Ecosystem Assessment, 2005), respectively, and roughly relate to biodiversity, ecosystem structure and function, conservation, and food yield outcomes. For each of the EPFs, the relative change from end to start of the simulation period (40 years) under the two climate change scenarios was calculated. To assess effectiveness, the relative change between the alternative management scenarios and current management was calculated. Based on model validation where the mean value of the 50 simulations described historical coral cover trajectory well (Supplementary Text S3), we used the scenario means for each parameter that described the EPF (see below) for each reef cell. We then present the resulting EPF values as a mean (and standard error) for all reef cells. We also show the spatial variation of each EPF under the different scenarios visually in maps.

\section{State of the Reef}

The ecological status of Maui Nui reefs was represented by the "State of the Reef," a supporting ecosystem service defined as:

$$
\sum_{i=1}^{5} w_{i} \times R_{i}
$$

where $w_{i}$ is the weighting factor of each $R_{i}$, with $R_{i}$, representing the standardized value of five key indicators of reef structure: coral cover, macroalgal cover, total fish biomass, fish richness, and coral richness (Supplementary Text S4). An expert survey defined weighting factors as: (i) coral cover 30\%; (ii) coral richness 20\%, (iii) fish biomass 20\%; (iv) fish richness $15 \%$ and (v) macroalgal cover 15\% (Van Beukering and Cesar, 2004). Coral richness and fish richness values were based on Orlando and Yee (2017). The ecological indicator scores were scaled to the maximum value of each indicator. 
TABLE 2 | Descriptions of 16 forecast simulations from 2010 to 2050.

\begin{tabular}{llll}
\hline Scenario type & Scenario name & Description & Primary parameters modification \\
\hline No additional management, & CM: Current Management & Simulation of current management $\sim 2 \%$ no-take & See Supplementary Text S2 for base \\
no climate-related stressors & & $\begin{array}{l}\text { MPAs and } \sim 10 \% \text { as MPA) under projected increase } \\
\text { in human population with corresponding increased }\end{array}$ & parameters
\end{tabular}

\begin{tabular}{llll}
\hline $\begin{array}{l}\text { Land-based management, } \\
\text { no climate-related stressors }\end{array}$ & A1: High sediment mitigation & Sediment input reduced compared to & A1: 0.38 * Current Management \\
& A2: Low sediment mitigation & Current situation for each scenario & A2: 0.94 * Current Management
\end{tabular}

Marine-based management, B1_30 Additional MPAs on randomly selected reef areas no climate-related stressors

B1_30
comprising $30 \%$ of total reef area; new areas designated as no-take

B2_30

B3_10

B4_20
As B1_30 with a different set of randomly selected reef areas

Additional MPAs created of areas encompassing the top $10 \%$ of coral cover and fish biomass; new areas designated as no-take

Additional MPAs created as under B3_10 but encompassing top $20 \%$, and current MPAs also designated as no-take
No additional management, climate-related stressors
C1: Current Management combined with high frequency of bleaching events

C2: Current Management combined with low frequency of bleaching events
Severe and less severe climate-related scenarios. Both have hurricanes every 10 years. The severe (C1) scenario has increased bleaching-related coral mortality events every 2 years and the less severe scenario (C2) every 5 years. Both scenarios have no implementation of additional management strategies (Current Management).
All parameters set to Current Management values with fishing effort restricted according to size of MPAs

\begin{tabular}{ll}
\hline Management and & (D) Least effort sediment \\
climate-related stressors & mitigation methods and MPA \\
& expansion under climate-related \\
stressors
\end{tabular}

Management and climate-related stressors
(E) High effort sediment mitigation methods and 30\% MPA expansion under climate-related stressors
Combinations of fishery management B3_10 (top $10 \%$ coral cover and fish biomass are added as no-take MPAs) and land-based management A2 (low erosion mitigation efforts) with bleaching-related coral mortality events every 2 (D1) and 5 years (D2)

Combinations of fishery management B2_30 (30\% randomly selected reef areas are added as no-take MPAs) and land-based management A1 (high erosion mitigation efforts) with bleaching-related coral mortality events every 2 (E1) and 5 years (E2)

As Scenario E with an additional $20 \%$ reduction in fishing effort of piscivores and bleaching-related coral mortality events every $2(\mathrm{~F} 1)$ and 5 years (F2)
- hfreq = 10; mean number of years between hurricanes

- hdam_C = 0.49; factor by which coral cover is reduced during hurricane events

- hdam_M = 0.49; factor by which macroalgal cover is reduced during hurricane event

- cmfreq $=1$ or 5 ; mean number of years between bleaching events

- cm_C =0.3; factor by which coral cover is reduced during coral mortality events

- Parameters hfreq, hdam_C, hdam_M, and cm_C as in scenarios C1 or $\mathrm{C} 2$

- 0.94 * CM sediment input (A2)

- Additional 10\% MPAs (B3_10)

- Parameters hfreq, hdam_C, hdam_M, and cm_C as in scenarios $\mathrm{C} 1$ or $\mathrm{C} 2$

- 0.38 * CM sediment input (A1)

- Additional 30\% MPAs as no-take (B2_30)

- Parameters hfreq, hdam_C hdam_M, and cm_C as in scenarios $\mathrm{C} 1$ or $\mathrm{C} 2$

- 0.38 * CM sediment input (A1)

- Additional 30\% MPAs as no-take (B2_30)

- Reduced total piscivore fishing by $20 \%$

\footnotetext{
Parameters are specified in Supplementary Text S2.
} 


\section{Trophic Integrity}

The trophic integrity was estimated by the ratio of calcifiers [corals $(C)$ and CCA] and fleshy algae [turf $(T)$ and macroalgae $(M A)]$ and the trophic level of the fish community with herbivores $(H)$ having a trophic level of 2 and piscivores $(P)$ a trophic level of 4 :

$$
0.5 *\left(\frac{C+C C A}{T+M A}\right)+0.5 *\left(2 * \frac{H}{H+P}+4 * \frac{P}{H+P}\right)
$$

Ecological indicator scores were scaled to the maximum value of each indicator.

\section{Fisheries Production}

Present-day predicted biomass of resource fish species (defined as species that had $\geq 450 \mathrm{~kg}$ of average annual harvest from 2000 to 2010 in the state of Hawaici) was calculated as a ratio of total fish biomass (McCoy et al., 2018). This ratio was assumed to remain constant in the course of fluctuations in total fish biomass. Fisheries Production, therefore, represents the biomass of resource fish, a potential ecosystem service.

\section{Fisheries Landings}

The model directly calculates fish catch as a function of available fish biomass (basemap input layer) maximum fishing effort, and accessibility (last two dynamics estimated for Maui Nui, Supplementary Text S3). Fisheries Landings is a provisional ecosystem service.

\section{RESULTS}

\section{Local Management Strategies Can Attenuate Declines in Ecological Outcomes} Under the Current Management scenario, coral cover declined and was replaced by macroalgal cover (Figure 3A). Piscivore biomass also declined, to less than half the initial biomass but could recover in the last decade (Figure 3B), likely due to a shift in catch composition to predominantly herbivorous fishes (Figures 3C,D).

A continuation of current management attenuated the downward trend in coral cover. Comparing land-based management scenarios (high and low sediment mitigation, A scenarios) and marine-based management scenarios (additional no-take MPAs, B scenarios), sediment mitigation strongly impacted benthic composition, whereas fisheries management impacted fish biomass (Figure 4). For example, reduction of sediment input slowed the decline in coral cover compared to Current Management (Supplementary Figures S5.1, 5.2). Sediment mitigation exhibited a mixed effect on algal cover: it limited the space occupied by turf algae and CCA, but it had negligible effect on macroalgal cover (Figures S5.3-5.5). Fish biomass also responded to a change in benthic composition. In the high mitigation sediment reduction scenario (A1), herbivorous fish biomass declined slightly compared to Current Management (Figure S5.6) whereas piscivore biomass declined slightly under the low mitigation scenario (A2).

Marine-based management strategies had minimal impact on the trajectories of coral cover compared to the Current
Management scenario (Figure 4, Figures S5.1, 5.2). CCA, however, did respond to MPA designations with decreases under one of the 30\% MPA scenario (B1) and 20\% MPA scenario (B4) but increased slightly under the other 30 and 10\% MPA scenario (B2, B3 resp.; Figure 4, Figure S5.5). Interestingly, fish biomass hardly changed under MPA scenarios (Figure 4, Figure S5.6). The large error bar on the piscivore biomass also reflects the sensitivity of the model to the parameterization of fish-related variables.

The expansion of current MPA boundaries to include areas encompassing the top 10\% (B3) and 20\% (B4) of fish biomass and coral cover or the randomly placed 30\% MPAs (B1 and B2) showed no clear pattern in the results. Striking is that the placement of the 30\% no-take MPAs had opposite outcomes for fish catch which declined by up to $20 \%$ under B2 and increased to $32 \%$ under B1 (Figure 4) for herbivore and piscivore catches, respectively.

\section{Local Management Strategies Have Mixed Results Under Climate-Related Stressor Scenarios}

Model projections resulted in steep declines in coral cover from current levels, especially under the more severe climaterelated stressors scenarios where hurricanes and thermal stress led to coral mortality (Figures S5.1, 5.2). Local management did somewhat mitigate the effects of a changing climate, with slightly more benefit (i.e., lower net loss) under the more severe scenario (Figure 5). Climate-related stressors were projected to have a positive effect on herbivorous fish biomass (Figure S5.6 "base"), while local management buffered losses in piscivorous fish biomass, which then resulted in decreased herbivore biomass especially under the stricter management scenarios (E and F; Figure S5.6 "scenario"). However, due to the large fluctuations in fish biomass, these differences in herbivore biomass were not statistically significant (Figure 5). Under all climate-related stressors and management scenarios (D-F), herbivores increased with $5-11 \mathrm{t} / \mathrm{km}^{2}$ across Maui Nui from 2015 to 2050 (Figure S5.6). These increases represent an ecologically valid outcome, given the overall increases in turf and macroalgal cover, which are food sources for herbivorous fishes (Figure 2). Hurricanes did result in temporary "dips" in the overall increase in macroalgal cover under both climaterelated stressors scenarios but due to their relatively high growth rate, macroalgae recovered within a year. In general, under the climate scenarios, local management benefited corals and piscivores with a tradeoff in fisheries catches. These results were more pronounced under the stricter management scenario $\mathrm{E}$ and $\mathrm{F}$, and under the higher climate stress scenario (Figure 5).

\section{Implications for Ecosystem Goods and Services}

Under a future scenario of severe climate stress and current management (C1, Figure 6), Trophic Integrity declined by $15 \%$ and Fisheries Landings by $6 \%$. However, in the entire Maui Nui area, State of the Reef and Fisheries Production increased by up to $41 \%$, but with large spatial variation. Across all scenarios, 

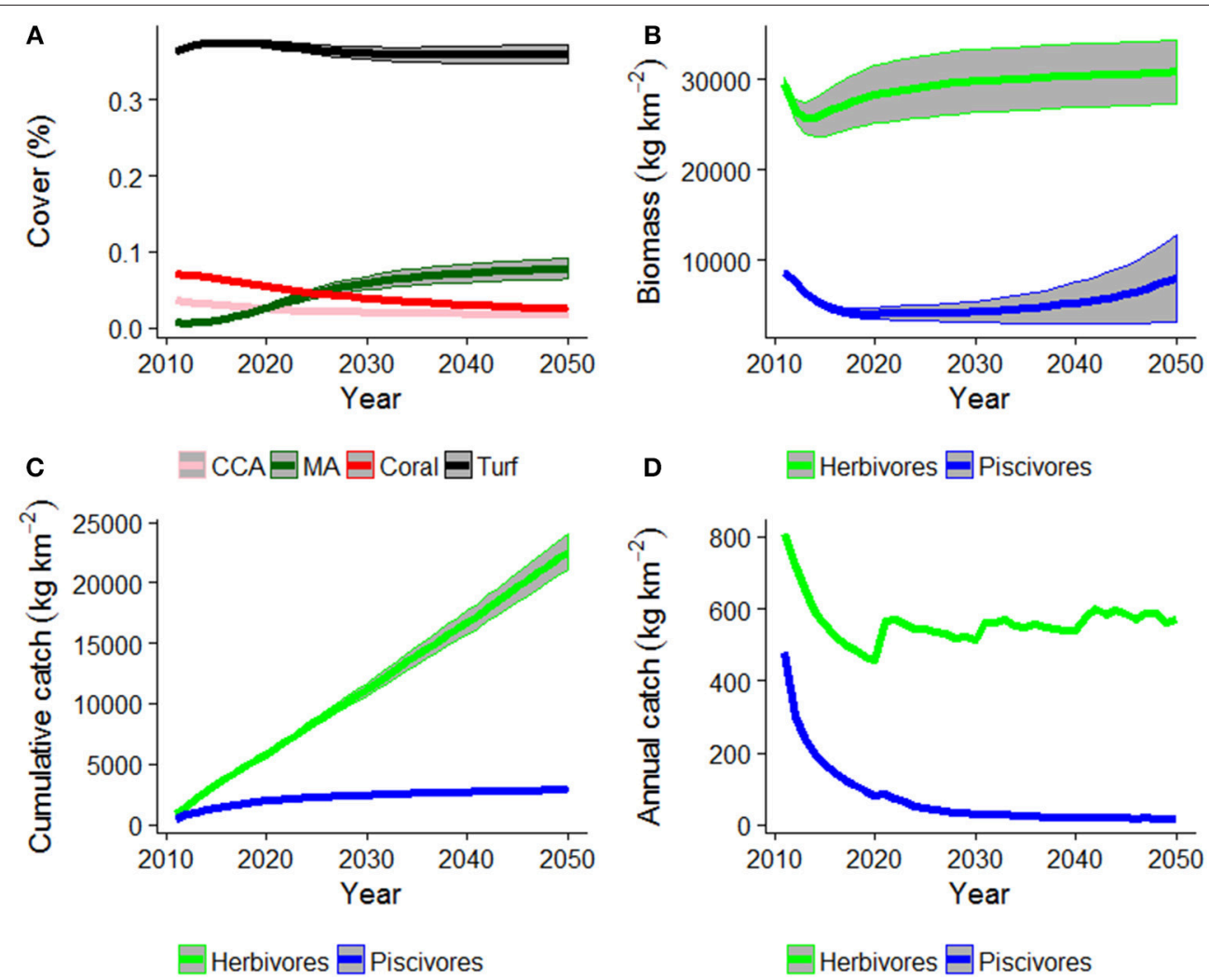

FIGURE 3 | HIReefSim model estimated trajectories of (A) cover of crustose-coralline algae (CCA), macroalgae (MA), coral, and turf algae, (B) fish biomass, (C) fish cumulative catch, and (D) annual catches under the Current Management scenario. Shaded area is \pm 1 standard error of the mean.

local management improved the Trophic Integrity of the reef (or dampened the decline) and the State of the Reef under the less severe climate change scenarios but had slightly negative effect on State of the Reef under severe climate change as well as on Fisheries Production and Fisheries Landings (Figure 6).

Local management could not prevent a decline in the Trophic Integrity; however, it did decrease the trajectory. Comparing Current Management (C1) to increasingly stringent local management of sediment and fishing stressors under severe climate-related stressors (D1, E1, and F1; darker colors in Figure 6), shows a trend of diminished decline in Trophic Integrity. Even larger improvements were evident under less severe climate-related stressors.

State of the Reef and Fisheries Production displayed improved results under all scenarios due to the increase in herbivore biomass that are components of these EPF. Model results showed a counterintuitive trend with management as both EPFs had lower values under severe climate scenarios compared to current management and Fisheries Production also decreased under less severe climate change. These lower values can be attributed to the smaller decreases in piscivore biomass due to management, leading to more predation pressure on herbivorous fish (Supplementary Figures S5.6, S5.7). On the other hand, State of the Reef clearly improved with local management under the less severe climate change scenarios (Figure 6).
Fisheries Landings were projected to decrease more compared to current management (C), especially under the scenarios including 30\% MPAs (E, F). Due to the low piscivore biomass, an additional $20 \%$ reduced piscivore pressure (F) had almost no additional effect in landings (Figure 6).

Looking at the effectiveness of local management scenarios by comparing the end states of the EPFs of each scenario relative to current management, both the Trophic Integrity of the reef as well as the State of the Reef can benefit from additional management especially under less severe climate change (Figure 7). Fisheries Production fared less well, likely because of the increase in piscivore biomass (resulting in less herbivores) and the largest tradeoff was in Fisheries Landings.

Spatial variation in the results of management can provide insights into where to target local management. For example, the southern coastlines of Moloka' $i$ and Maui showed declines for the State of the Reef and strict local management had little effect (Figure 8). By contrast, under less severe climate change, local management improved State of the Reef along the same coastlines (Figure 9). However, there were also some places (designated in blue) where management exacerbated declines. Generally, management had a positive impact along most of the coastlines (red areas in Figures 8, 9).

Spatial patterns in Fisheries Production showed improvement under all scenarios and along most coastlines but less so 


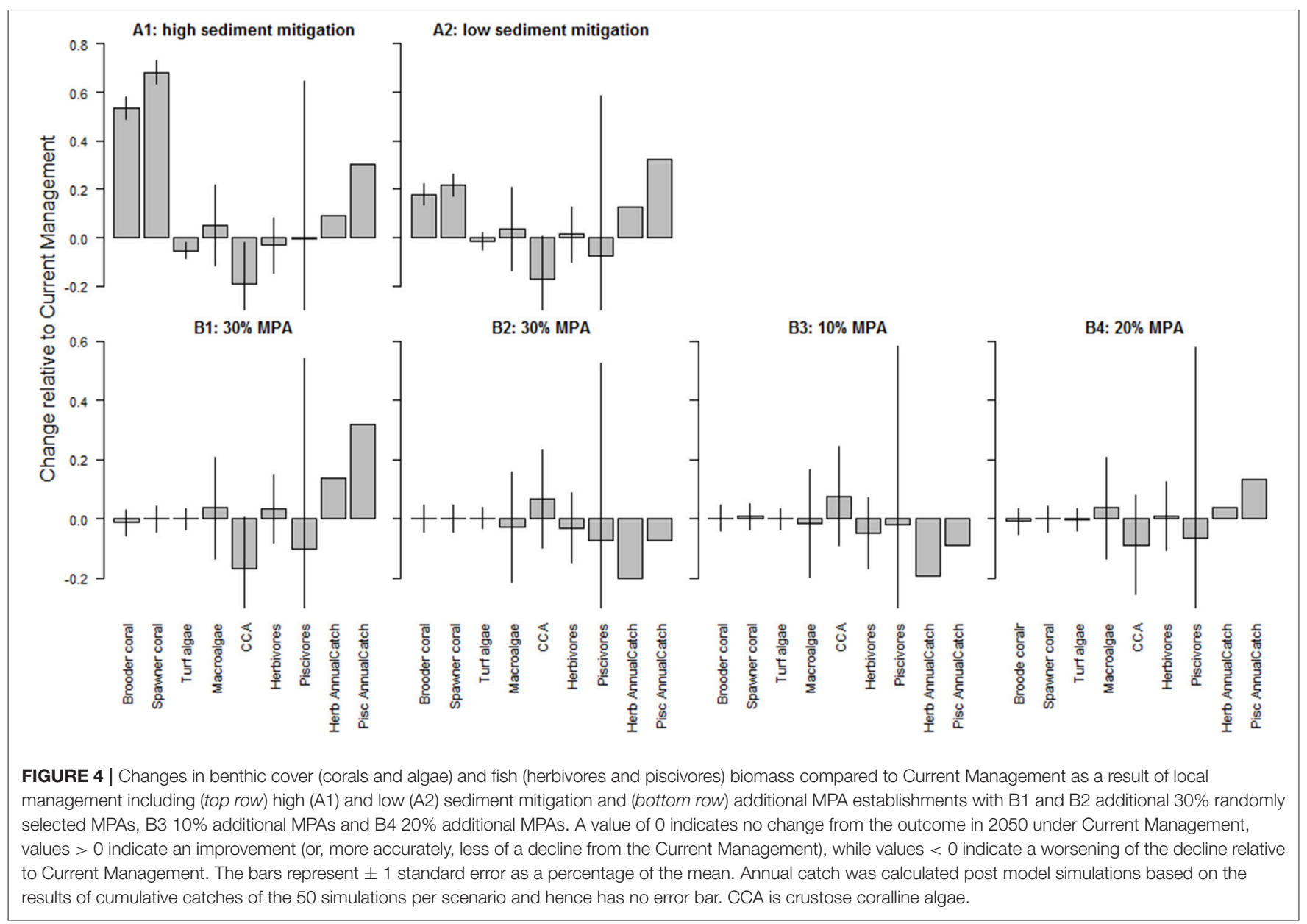

along the northern coastline of Moloka' $i$ (we note that this area had relatively high biomass at the initialization of the scenario runs; Figure 10). Although in general many areas showed improvement, all coastlines also experienced losses; up to $100 \%$ in some places (Supplementary Figures S6). Management that included a $20 \%$ reduction in piscivore fish catches (Scenario F) tended to decrease overall Fisheries Production due to an increase in piscivores that preyed on herbivores (Supplementary Figures S6). At the same time, certain areas showed improvements with management partially due to spatial arrangement of the MPAs.

Trophic Integrity improved most along the southern coastline of Moloka'i and all around Maui (Supplementary Figures S6). As with the State of the Reef, the severity of climate change greatly influenced the results with much higher improvements under the less severe climate change scenarios.

\section{DISCUSSION}

Marine resource managers are challenged with accounting for the cumulative effects of local and global stressors on coral reef ecosystems and the valuable services reefs provide to society. However, environmental conditions and human use can result in considerable spatial variability of both reef fish biomass as well as benthic community (Williams et al., 2015; Cinner et al., 2016; Gorospe et al., 2018). Managers can use spatially-explicit decision-support tools to prioritize areas of high ecosystem service value that could benefit from action. Scenarios of future conditions can guide decision-makers as to which of these actions are robust to projected climate impacts.

We evaluated the impacts of land-based vs. marine-based management and local vs. global stressors by assessing the relationships between different functional groups over time and under various management strategies and severities of climate-related stressors. As a metric for the effectiveness of these different strategies, four EPFs were used to model changes in ecosystem services; these ecosystem services best represented the economic interests of the State of Hawai $i$ pertaining to reef structure and resilience and reef-derived benefits.

Management of Hawai'i's valuable nearshore areas in the face of local and global stressors will need to be adaptive to changing conditions. As more people choose to live in or visit Hawai ${ }^{i}$, local stressors will continue to mount, sometimes in unexpected places or ways. Impacts from global climate change offer another dimension of surprise. HIReefSim is an important tool to support adaptive local marine resource decision making. Our results suggest that policies are needed 


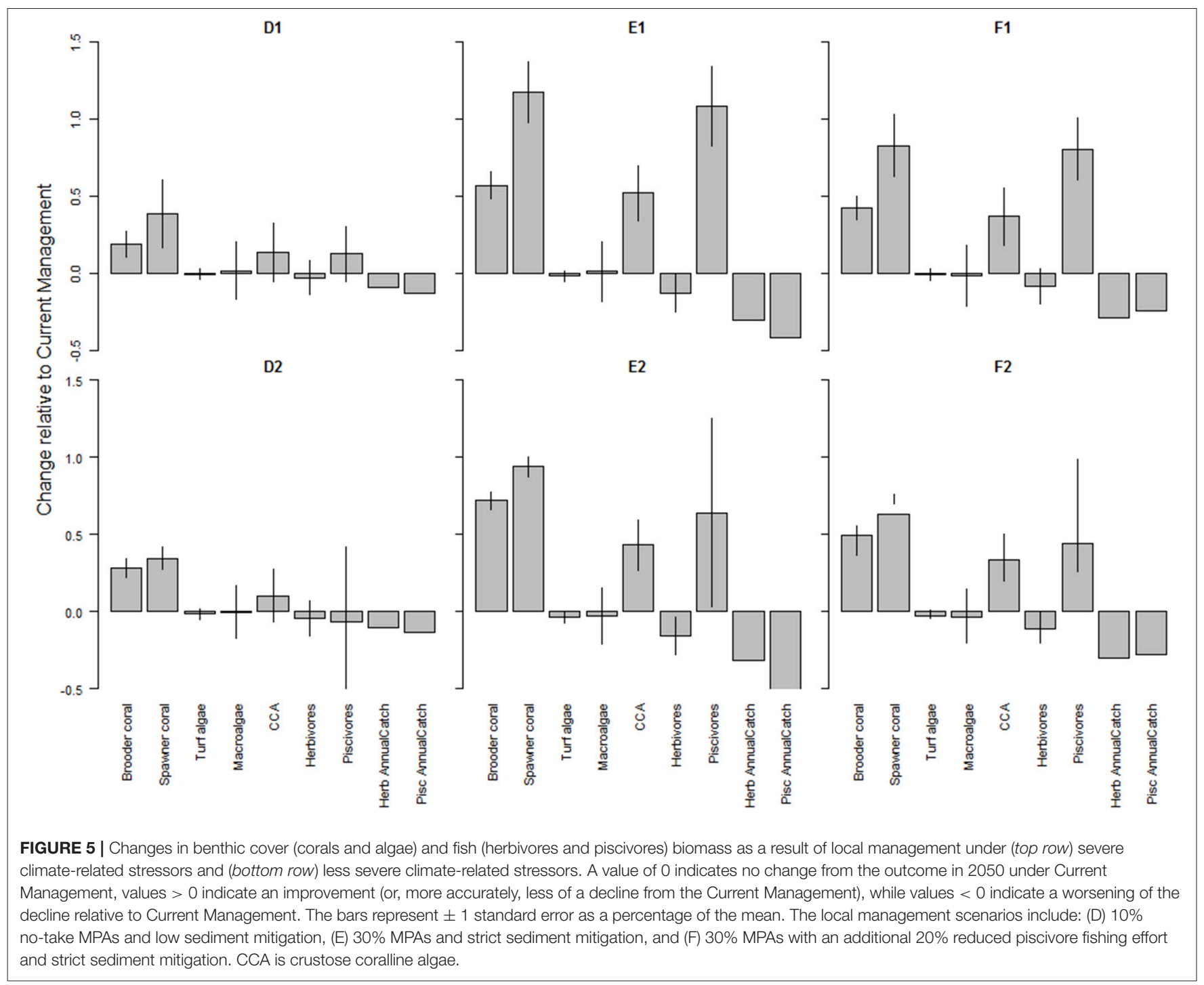

to mitigate local threats, and that these policies should consider future risks of impacts from climate-related stressors, such as changing hurricane patterns and coral bleaching, and likely also sea level rise. In 2016, the governor of Hawai' $i$ pledged to "effectively manage" $30 \%$ of the marine areas along the coastline by 2030, launching a multi-year marine spatial planning process. Key results from our analysis offer a number of suggestions for adapting near-term management to long-term conditions. First of all, strict management of all local pressures (i.e., land-based and fisheries) is needed everywhere-not just across $30 \%$ of the nearshore area-to obtain the best results for reef state and trophic integrity under all climate change scenarios. Secondly, place matters. We found that spatial variation in the effects of local management was particularly high for reef state and fisheries production, and moderate for trophic integrity and fisheries landings, suggesting that fine-tuning place-based management could improve outcomes.

\section{Does Local Management Matter in the Face of Climate-Related Stressors?}

Yes, despite a decline in Trophic Integrity and State of the Reef EPFs, both these EPFs displayed a buffering effect of strict management on the degradation of coral reefs, mostly under the less severe climate change scenarios. However, as a tradeoff, Fisheries Landings decreased overall compared to today's levels but the maximum decrease was just under $6 \%$ (Figure 6). Average Fisheries Production increased between $42 \%$ (scenario C2) and 38\% (scenario D2) mostly due to the increases in herbivore biomass correlated with increases in turf algae. In absolute terms, local sediment control was particularly critical in slowing the decline of reefs under severe climate change. In these scenarios, coral cover was more prone to decline rapidly, which underscores both the importance of reducing greenhouse gases and implementing proactive, stringent management policies to mitigate declines in coral cover (Ortiz et al., 2014; Hughes et al., 2017). These results correspond to other modeling 

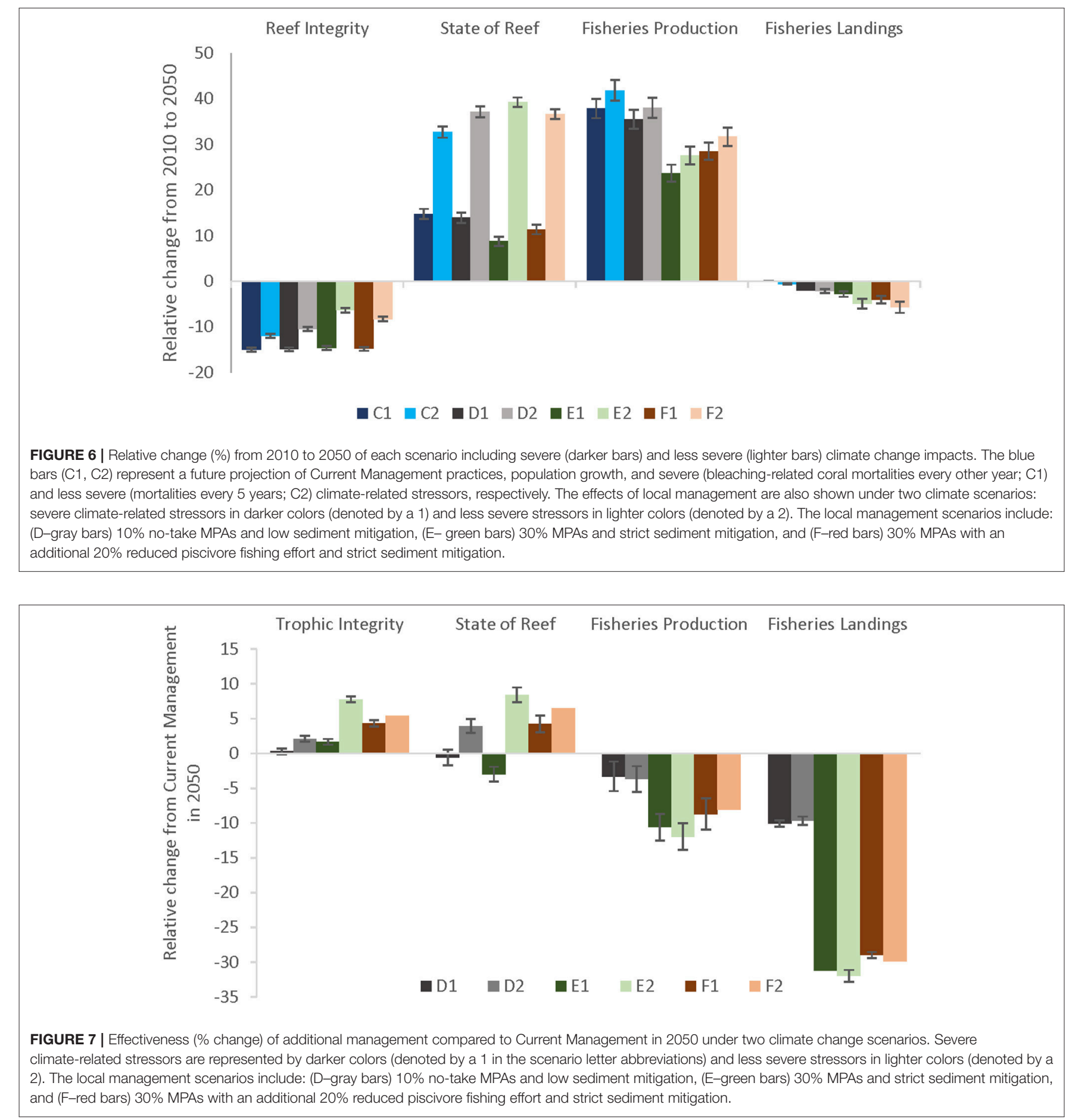

studies. Weijerman et al. (2015) showed that reefs in Guam would experience devastating declines under projected annual bleaching events despite local management directed at reduced land-based pollution and fishing. The same result was found for a Caribbean reef where, under the projected greenhouse gas emissions of a business-as-usual scenario, corals failed to recover from frequent bleaching events (Ortiz et al., 2014). Reducing sediments is not a complete solution given that nutrients and other contaminants of concern are still present and may have a very different spatial signature. We focused on sediment impacts for this project based on the completeness and trustworthiness of available data layers, but future efforts may consider the impacts of other sources of land-based pollution.

Herbivores appeared to fare well under climate-related stressors as coral cover declined and algal cover increased (Figures 6, 7). The strong correlation between algae and 


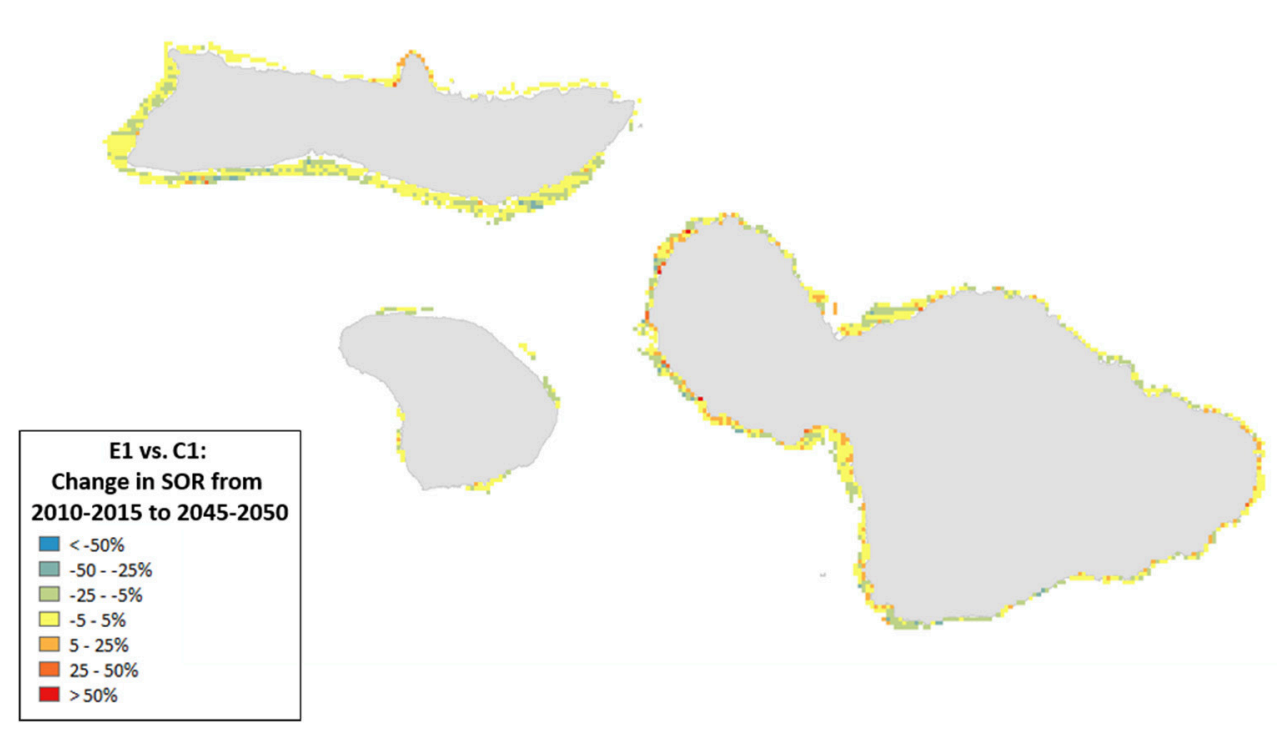

FIGURE 8 | Ratio of the change in State of the Reef (2010-2050) for scenario E1 (high sediment mitigation, 30\% MPAs) compared to C1 (Current Management) under severe climate-related stressors. A value of 0 indicates no change from the outcome in 2050 under Current Management, values $>0$ indicate an improvement (or, more accurately, less of a decline from the Current Management), while values $<0$ indicate a worsening of the decline relative to Current Management.

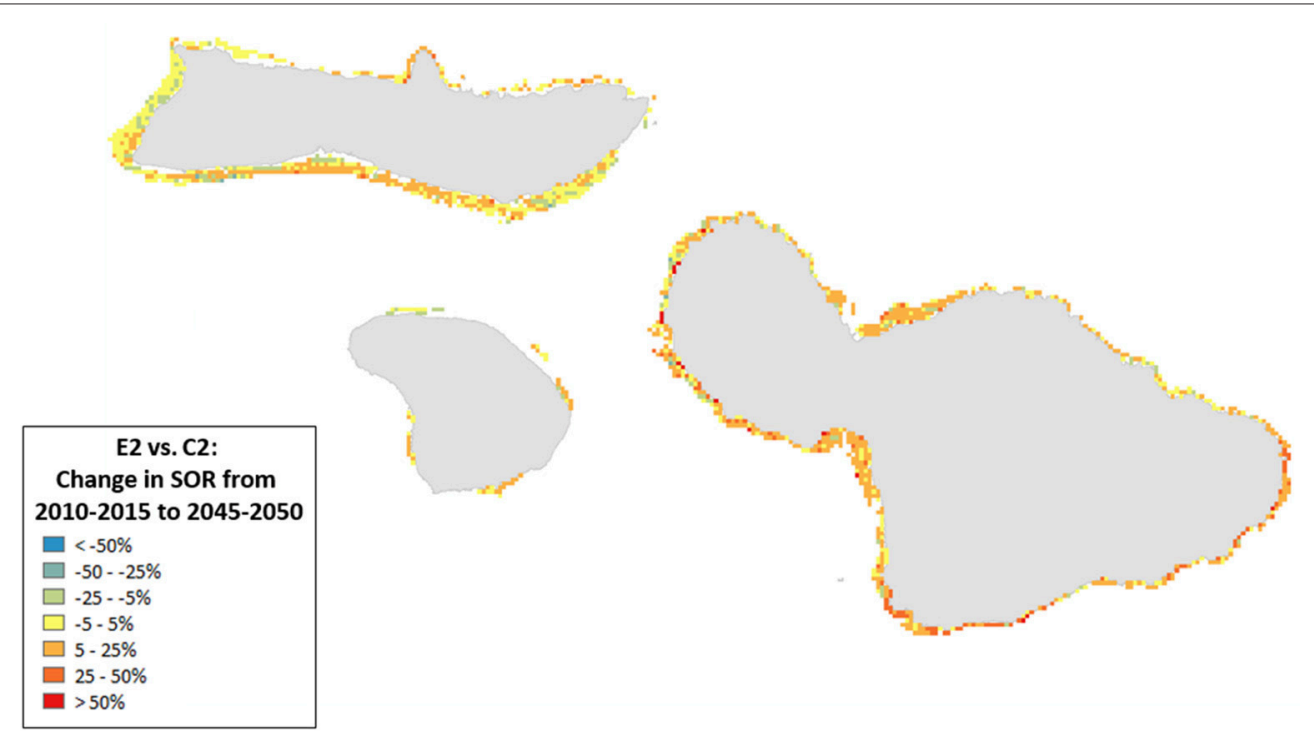

FIGURE 9 | Ratio of the change in State of the Reef (2010-2050) for scenario E2 (high sediment mitigation, 30\% MPAs) compared to C2 (Current Management) under less severe climate-related stressors. A value of 0 indicates no change from the outcome in 2050 under Current Management, values $>0$ indicate an improvement (or, more accurately, less of a decline from the Current Management), while values $<0$ indicate a worsening of the decline relative to Current Management.

herbivores could be explained by the control of bottom-up, not top-down, mechanisms. A comparison of piscivore biomass in the populated Main Hawaiian Islands (MHI) with the non-fished Northwestern Hawaiian Islands (NWHI) shows that piscivore biomass was about 10-44 times higher in the NWHI (Williams et al., 2011). Even within the MHI, relatively remote and inaccessible locations had about five times the biomass of apex predators compared to more open areas (Williams et al., 2008).
Thus, the low biomass of piscivores observed in the MHI could explain why top-down effects may not be strong enough to explain some of the results, and suggests that strict fishery management is required to improve predation as an ecosystem function (Figure 5, Figure S5.7).

Alternatively, the increase in piscivores could be viewed as an undesired outcome since more piscivores led to elevated predation pressure on herbivores, reducing their biomass and 


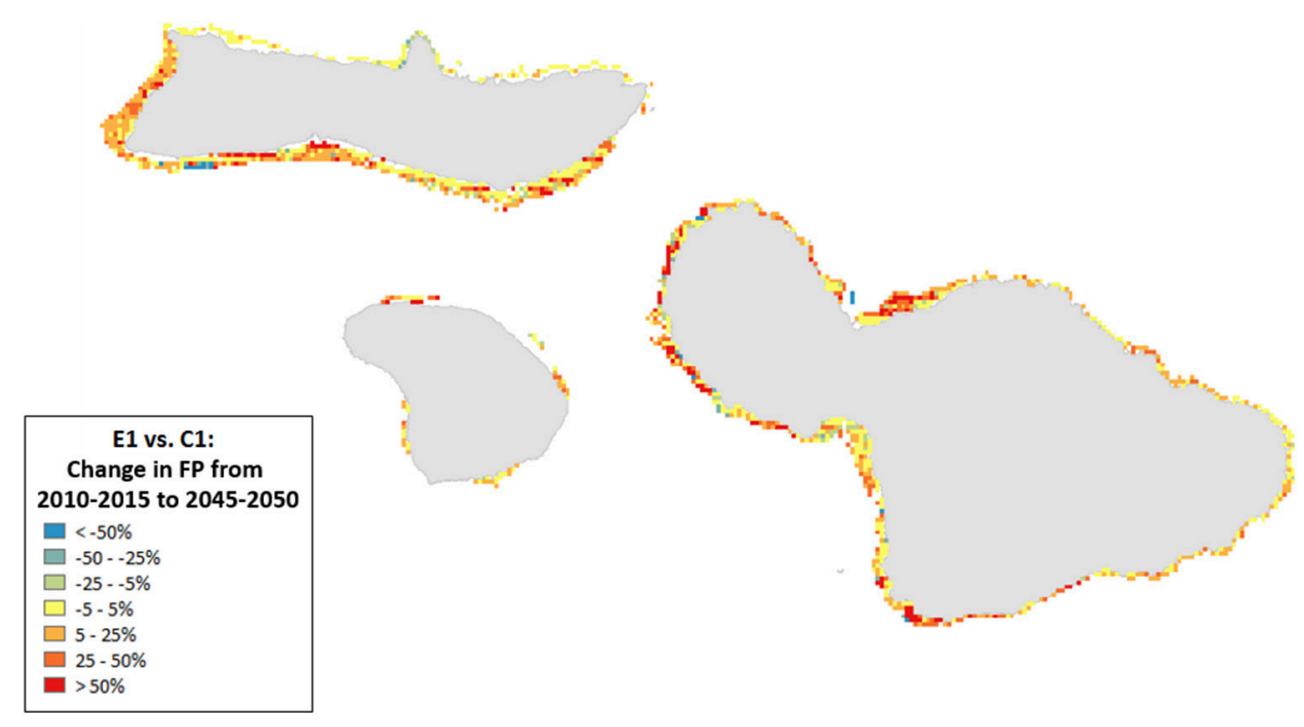

FIGURE 10 | Ratio of change in Fisheries Production (2010-2050) for scenario E1 (high sediment mitigation, 30\% MPAs) compared to C1 (Current Management) under severe climate-related stressors. A value of 0 indicates no change from the outcome in 2050 under Current Management, values $>0$ indicate an improvement (or, more accurately, less of a decline from the Current Management), while values $<0$ indicate a worsening of the decline relative to Current Management.

the overall Fisheries Production (Figures 5-7). Ecologically, a higher trophic level (piscivores have a trophic level of $3.5-5$ compared to a level of 2 for herbivores) of the fish community represents an ecosystem that is energetically more optimal and mature (Graham et al., 2017). Hence, for ecological reasons, one might want to strive to obtain a fish community with a high composition of piscivores. Economically, this also makes sense as in general piscivores sell for a higher price $(\$ 3.5-\$ 5$ per pound) compared to herbivores ( $\$ 2-\$ 3.5$ per pound). Thus, although the results indicate a lower Fisheries Production under local management scenarios, this is not necessarily a bad thing; the Trophic Integrity of the Reef improved with more stringent management (E, F; Figure 7), and the reduced catch may not translate into large economic losses.

Wide-scale spatial variability across Maui Nui was projected for the EPFs, with declines of up to $100 \%$ across the northern shores of Maui and Moloka'i for Fisheries Production, and large declines in State of the Reef along southern and eastern shores (where the impacts of hurricanes were projected to be highest), highlighting the importance of identifying areas where management will likely be most successful.

\section{How Important Is It to Consider Both Land- and Marine-Based Threats in Local Management Action?}

Effectively managing the entire coral reef ecosystem requires the combination of both land-based and marine-based approaches. Land-based management was most beneficial for the benthic community, especially coral cover, whereas marine-based management not only decreased macroalgal cover, opening up substrate for reef calcifying CCA, but most notably decreased the downward trend in piscivore biomass (Figure 3). Of equal importance in evaluating the effectiveness of marine-based management (MPAs) are the often-conflicting extraction and conservation objectives (Dichmont et al., 2013). If the objective of MPAs is to improve coral cover, MPA establishment proved less effective than reducing land-based pollution (Figure 3). MPAs can enhance the resilience of coral reef ecosystems through trophic interactions (Mellin et al., 2016) or lead to small increases in coral cover (Graham et al., 2011), but reducing the main local stressors that drive coral decline directly (such as sediment inputs) is more effective (ISRS, 2004) as the model results also showed. For maintaining or increasing key ecosystem functions under the projected impacts of climate-related stressors, no single management tool was effective, but a combination of both land-based and marine-based management was needed as well as a reduction in greenhouse gas emissions (Figures 57). These modeling results are corroborated by other studies (Dichmont et al., 2013; Weijerman et al., 2015; Arias-Gonzalez et al., 2017).

Random placement of no-take MPAs may not benefit the overall benthic community (Figure 3). For example, the 30\% MPA designation in scenario B1 mitigated loss of fish biomass less than B2 for fish biomass, but improved the fate of corals (Figure 3). Placing MPAs in areas with currently the highest 10\% of fish biomass and coral cover (B3) also increased the piscivore biomass but when (almost) doubling this area by making the current MPAs also no-take MPAs (B4), piscivore biomass did not double and catches stayed very similar (Figure 4). Likely, the areas which currently have the highest fish biomass are already somewhat exempt from high fishing pressure, either because they are difficult to access or because only few people live close by, underscoring the importance of MPA placements. A separate issue is whether MPAs can achieve desired outcomes, as that also depends largely on strong governance (Cinner et al., 2016) and compliance (Gill et al., 2017). 


\section{CONCLUSIONS}

Overall, in the face of global threats, local management had mixed results for the ecosystem goods and services the reef provides. It abated the decline in Trophic Integrity of the reef and improved State of the Reef especially when both land-based and marine based approaches were combined but reducing greenhouse gas emissions is essential to avoid catastrophic loss of ecosystem services. Management that was more stringent required trading off Fisheries Production and Landings. By including extraction and reef resilience objectives in ecosystem goods and services, we provide a generalizable tool to clearly evaluate the tradeoff of these conflicting goals under various management and climate-related stressors. Based on the limitations of the model structure, a cautionary interpretation of the model's predicted long-term trajectory should be taken. Future work may want to improve the resource fish ratio, which we assumed to stay constant over the entire period. This assumption is unrealistic because fishers are likely to target specific species (e.g., jacks or other piscivores), causing community structure to shift. Furthermore, the results from the small number of MPA scenarios call for more thorough analysis, particularly with respect to their interaction with land-based pollution control. The model could also be used for evaluating the relative effectiveness of different fisheries management strategies, e.g., targeting different trophic groups. A similar endeavor could focus on compliance within those MPAs to test the effectiveness of restriction levels. Results of these improvements could greatly benefit the ongoing discussions of how to manage $30 \%$ of the coastline effectively.

\section{DATA AVAILABILITY STATEMENT}

The raw data supporting the conclusions of this manuscript are available at http://olesonlab.org/data/.

\section{REFERENCES}

Alvarez-Filip, L., Dulvy, N. K., Gill, J. A., Côté, I. M., and Watkinson, A. R. (2009). Flattening of caribbean coral reefs: region-wide declines in architectural complexity. Proc. R. Soc. B Biol. Sci. 276, 3019-3025. doi: 10.1098/rspb.2009.0339

Álvarez-Romero, J. G., Pressey, R. L., Ban, N. C., Vance-Borland, K., Willer, C., Klein, C. J., et al. (2011). Integrated land-sea conservation planning: the missing links. Annu. Rev. Ecol. Evol. Syst. 42, 381-409. doi: 10.1146/annurev-ecolsys-102209-144702

Arias-Gonzalez, J. E., Fung, T., Seymour, R. M., Garza-Perez, J. R., AcostaGonzalez, G., Bozec, Y.-M., et al. (2017). A coral-algal phase shift in mesoamerica not driven by changes in herbivorous fish abundance. PLoS ONE 12:e0174855. doi: 10.1371/journal.pone.0174855

Arkema, K. K., Abramson, S. C., and Dewsbury, B. M. (2006). Marine ecosystembased management: from characterization to implementation. Front. Ecol. Environ. 4, 525-532. doi: 10.1890/1540-9295(2006)4[525:MEMFCT]2.0.CO;2

Bagstad, K. J., Semmens, D. J., Waage, S., and Winthrop, R. (2013). A comparative assessment of decision-support tools for ecosystem services quantification and valuation. Ecosyst. Serv. 5, 27-39. doi: 10.1016/j.ecoser.2013. 07.004

\section{AUTHOR CONTRIBUTIONS}

MW, LV, KO, JD, and SY: study design. KF, JL, and MD: data sources. MW, LV, KV, and SY: Coding. MW, LV, and KO: analysis/Interpretation. MW wrote the first draft of the manuscript. All authors wrote sections of the manuscript, contributed to manuscript revision, read and approved the submitted version.

\section{FUNDING}

Funding for this research was provided by PICSC G13AC00361, NOAA CRCP NA13NOS4820020, and NOAA CRCP NA17NOS4820076.

\section{ACKNOWLEDGMENTS}

The authors thank the providers of the input data used to build our models, in particular Johanna Wren for the connectivity matrix, the Hawai'i Monitoring and Research Collaborative for the underwater visual survey data, Bill Ward for regional hurricane impacts, as well as, contributions to the predictive model development by Kosta Stamoulis, Matt Poti, Bryan Costa, and Matt Kendall. The authors also thank Tayler Massey and Megan Barnes for their assistance and/or advice in the completion of this work and Brett Taylor and two reviewers for providing comments on earlier drafts. The views expressed in this article are those of the authors and do not necessarily reflect the views or policies of their respective agencies.

\section{SUPPLEMENTARY MATERIAL}

The Supplementary Material for this article can be found online at: https://www.frontiersin.org/articles/10.3389/fmars. 2018.00425/full\#supplementary-material

Barbier, E. B., Hacker, S. D., Kennedy, C., Koch, E. W., Stier, A. C., and Silliman, B. R. (2011). The value of estuarine and coastal ecosystem services. Ecol. Monogr. 81, 169-193. doi: 10.1890/10-1510.1

Bellwood, D. R., Hughes, T. P., Folke, C., and Nystrom, M. (2004). Confronting the coral reef crisis. Nature 429, 827-833. doi: 10.1038/nature02691

Brainard, R. E., Weijerman, M., Eakin, C. M. M., McElhany, P., Miller, M. W., Patterson, M., et al. (2013). Incorporating climate and ocean change into extinction risk assessments for 82 coral species. Conserv. Biol. 27, 1169-1178. doi: 10.1111/cobi.12171

Burke, L., Reytar, K., Spalding, M., and Perry, A. (2011). Reefs at Risk Revisited. Washington, DC: World Resources Institute.

Carlton, J. T., and Scanlon, J. A. (1985). Progression and dispersal of an introduced alga: Codium fragile ssp. tomentosoides (Chlorophyta) on the Atlantic Coast of North America. Bot. Mar. 28:155. doi: 10.1515/botm.1985.28.4.155

Cinner, J. E., Huchery, C., MacNeil, M. A., Graham, N. A. J., McClanahan, T. R., Maina, J., et al. (2016). Bright spots among the world's coral reefs. Nature 535, 416-419. doi: 10.1038/nature18607

Compton, J. E., Harrison, J. A., Dennis, R. L., Greaver, T. L., Hill, B. H., Jordan, S. J., et al. (2011). Ecosystem services altered by human changes in the nitrogen cycle: a new perspective for US decision making. Ecol. Lett. 14, 804-815. doi: 10.1111/j.1461-0248.2011.01631.x 
Daily, G. C., and Matson, P. A. (2008). Ecosystem services: from theory to implementation. Proc. Natl. Acad. Sci. U.S.A. 105, 9455-9456. doi: 10.1073/pnas.0804960105

DBEDT (2016). DBEDT 2014 Series. Popul. Econ. Proj. State Hawai i to 2040. Available online at: http://dbedt.hawaii.gov/economic/economic-forecast/ 2045-long-range-forecast/ (Accessed July 12, 2016).

de Groot, R. S., Wilson, M. A., and Boumans, R. M. J. J. (2002). A typology for the classification, description and valuation of ecosystem functions, goods and services. Ecol. Econ. 41, 393-408. doi: 10.1016/S0921-8009(02)00089-7

Delevaux, J. M. S. (2017). Data and Tools to Operationalize Ridge-to-Reef Management.Univ. of Hawaii at Manoa, Mgmt.Ph.D. dissertation. Dept. of Nat. Res. Envrin.

DeMartini, E. E., Anderson, T. W., Kenyon, J. C., Beets, J. P., and Friedlander, A. M. (2010). Management implications of juvenile reef fish habitat preferences and coral susceptibility to stressors. Mar. Freshw. Res. 61, 532-540. doi: 10.1071/MF09141

Dichmont, C. M., Ellis, N., Bustamante, R. H., Deng, R., Tickell, S., Pascual, R., et al. (2013). Evaluating marine spatial closures with conflicting fisheries and conservation objectives. J. Appl. Ecol. 50, 1060-1070. doi: $10.1111 / 1365-2664.12110$

Dollar, S. J., and Tribble, G. W. (1993). Recurrent storm disturbance and recovery: a long-term study of coral communities in Hawaii. Coral Reefs 12, 223-233. doi: 10.1007/BF00334481

Emanuel, K. (2005). Increasing destructiveness of tropical cyclones over the past 30 years. Nature 436, 686-688. doi: 10.1038/nature03906

Fung, T. C. (2009). Local Scale Models of Coral Reef Ecosystems for Scenario Testing and Decision Support. Univ. Coll. London, Fac. Maths Phys. Sci. Ph.D. dissertation.

Gill, D. A., Mascia, M. B., Ahmadia, G. N., Glew, L., Lester, S. E., Barnes, M., et al. (2017). Capacity shortfalls hinder the performance of marine protected areas globally. Nature 543, 665-669. doi: 10.1038/nature21708

Gorospe, K. D., Donahue, M. J., Heenan, A., Gove, J. M., Williams, I. D., and Brainard, R. E. (2018). Local biomass baselines and the recovery potential for Hawaiian coral reef fish communities. Front. Mar. Sci. 5:162. doi: $10.3389 /$ fmars.2018.00162

Graham, N. A. J., McClanahan, T. R., MacNeil, M. A., Wilson, S. K., Cinner, J. E., Huchery, C., et al. (2017). Human disruption of coral reef trophic structure. Curr. Biol. 27, 231-236. doi: 10.1016/j.cub.2016.10.062

Graham, N. A. J., and Nash, K. L. (2013). The importance of structural complexity in coral reef ecosystems. Coral Reefs 32, 315-326. doi: 10.1007/s00338-012-0984-y

Graham, N. A. J., Nash, K. L., and Kool, J. T. (2011). Coral reef recovery dynamics in a changing world. Coral Reefs 30, 283-294. doi: 10.1007/s00338-010-0717-z

Gratwicke, B., Speight, M. R., and Road, S. P. (2005). The relationship between fish species richness, abundance and habitat complexity in a range of shallow tropical marine habitats. J. Fish Biol. 66, 650-667. doi: 10.1111/j.0022-1112.2005.00629.x

Gurney, G. G., Melbourne-Thomas, J., Geronimo, R. C., Aliño, P. M., and Johnson, C. R. (2013). Modelling coral reef futures to inform management: can reducing local-scale stressors conserve reefs under climate change? PLoS ONE 8:e80137. doi: 10.1371\%2Fjournal.pone.0080137

Heithaus, M. R., Frid, A., Wirsing, A. J., and Worm, B. (2008). Predicting ecological consequences of marine top predator declines. Trends Ecol. Evol. 23, 202-210. doi: $10.1016 /$ j.tree.2008.01.003

Hoegh-Guldberg, O. (1999). Climate change, coral bleaching and the future of the world's coral reefs. Mar. Freshw. Res. 50, 839-866.

Hoegh-Guldberg, O., Andréfouët, S., Fabricius, K. E., Lough, J. M., Marshall, P. A., and Pratchett, M. S. (2011). "Vulnerability of coral reefs in the tropical Pacific to climate change," in Vulnerability of Tropical Pacific Fisheries and Aquaculture to Climate Change, eds J. Bell, J. Johnson, and A. Hobday (Noumea, New Caledonia: Secretariat of the Pacific Community), 251-296.

Hughes, T., Kerry, J., Álvarez-Noriega, M., Álvarez-Romero, J., Anderson, K., Baird, A., et al. (2017). Global warming and recurrent mass bleaching of corals. Nature 543, 373-377. doi: 10.1038/nature21707

Hughes, T. P., Graham, N. A. J., Jackson, J. B. C., Mumby, P. J., and Steneck, R. S. (2010). Rising to the challenge of sustaining coral reef resilience. Trends Ecol. Evol. 25, 633-642. doi: 10.1016/j.tree.2010.07.011
Hughes, T. P., Rodrigues, M. J., Bellwood, D. R., Ceccarelli, D., Hoegh-Guldberg, O., McCook, L., et al. (2007). Phase shifts, herbivory, and the resilience of coral reefs to climate change. Curr. Biol. 17, 360-365. doi: 10.1016/j.cub.2006.12.049

Hulme, P. (2005). Adapting to climate change: is there scope for ecological management in the face of a global threat? J. Appl. Ecol. 42, 784-794. doi: $10.1111 / \mathrm{j} .1365-2664.2005 .01082 . \mathrm{x}$

ISRS (2004). The Effects of Terrestrial Runoff of Sediments, Nutrients and Other Pollutants on Coral Reefs. Briefing Paper 3, International Society for Reef Studies.

Jokiel, P. L., and Coles, S. L. (1990). Response of Hawaiian and other Indo-Pacific reef corals to elevated temperature. Coral Reefs 8, 155-162. doi: 10.1007/BF00265006

Kapur, M. R., and Franklin, E. C. (2017). Simulating future climate impacts on tropical fisheries: are contemporary spatial fishery management strategies sufficient? Can. J. Fish. Aquat. Sci. 74, 1974-1989. doi: 10.1139/cjfas-2016-0200

Kennedy, E. V., Perry, C. T., Halloran, P. R., Iglesias-Prieto, R., Schönberg, C. H. L., Wisshak, M., et al. (2013). Avoiding coral reef functional collapse requires local and global action. Curr. Biol. 23, 912-918. doi: 10.1016/j.cub.2013.04.020

Levin, P. S., Kelble, C. R., Shuford, R. L., Ainsworth, C., Dunsmore, R., Fogarty, M. J., et al. (2013). Guidance for implementation of integrated ecosystem assessments: a US perspective. ICES J. Mar. Sci. 112, 1198-1204. doi: 10.1093/icesjms/fst112

Liu, X., and Xing, Y. (2012). Qualitative analysis for a predator prey system with holling type III functional response and prey refuge. Discret. Dyn. Nat. Soc. 2012:678957. doi: 10.1155/2012/678957

Maynard, J., van Hooidonk, R., Eakin, C. M., Puotinen, M., Garren, M., Williams, G., et al. (2015b). Projections of Climate Conditions that Increase Coral Disease Susceptibility and Pathogen Abundance and Virulence. Nat. Clim. Chang. 5, 1-8. doi: 10.1038/NCLIMATE.2625

Maynard, J. A., McKagan, S., Raymundo, L., Johnson, S., Ahmadia, G. N., Johnston, L., et al. (2015a). Assessing relative resilience potential of coral reefs to inform management. Biol. Conserv. 192, 109-119. doi: 10.1016/j.biocon.2015.09.001

McClanahan, T. R., Graham, N. A. J., and Darling, E. S. (2014). Coral reefs in a crystal ball: predicting the future from the vulnerability of corals and reef fishes to multiple stressors. Curr. Opin. Environ. Sustain. 7, 59-64. doi: 10.1016/j.cosust.2013.11.028

McCoy, K. S., Williams, I. D., Friedlander, A. M., Hongguang, M., Teneva, L. T., and Kittinger, J. N. (2018). Estimating nearshore coral reef-associated fisheries production from the main Hawaiian Islands using commercial and noncommercial data. PLoS ONE 13:e0195840. doi: 10.1371/journal.pone.0195840

Melbourne-Thomas, J., Johnson, C. R., Fung, T., Seymour, R. M., Chérubin, L. M., Arias-González, J. E., et al. (2011a). Regional-scale scenario modeling for coral reefs: a decision support tool to inform management of a complex system. Ecol. Appl. 21, 1380-1398. doi: 10.1890/09-1564.1

Melbourne-Thomas, J., Johnson, C. R., Perez, P., Eustache, J., Fulton, E. A., and Cleland, D. (2011b). Coupling biophysical and socioeconomic models for coral reef systems in quintana roo, Mexican Caribbean. Ecol. Soc. 16:23.

Mellin, C., MacNeil, M. A., Cheal, A. J., Emslie, M. J., Julian Caley, M., MacNeiil, M. A., et al. (2016). Marine protected areas increase resilience among coral reef communities. Ecol. Lett. 19, 629-637. doi: 10.1111/ele.12598

Millennium Ecosystem Assessment (2005). Ecosystems and Human Well-Being: Current State and Trends. eds R. Hassan and R. Scholes Washington, DC: Island Press.

Moberg, F., and Folke, C. (1999). Ecological goods and services of coral reef ecosystems. Ecol. Econ. 29, 215-233. doi: 10.1016/S0921-8009(99)00009-9

Murakami, H., Wang, B., Li, T., and Kitoh, A. (2013). Projected increase in tropical cyclones near Hawaii. Nat. Clim. Chang. 3, 749-754. doi: 10.1038/nclimate1890

Nelson, E., Mendoza, G., Regetz, J., Polasky, S., Tallis, H., Cameron, D. R., et al. (2009). Modeling multiple ecosystem services, biodiversity conservation, commodity production, and tradeoffs at landscape scales. Front. Ecol. Environ. 7, 4-11. doi: 10.1890/080023

Orlando, J. L., and Yee, S. H. (2017). Linking terrigenous sediment delivery to declines in coral reef ecosystem services. Estuaries Coasts 40, 359-375. doi: 10.1007/s12237-016-0167-0

Ortiz, J. C., Bozec, Y.-M., Wolff, N. H., Doropoulos, C., and Mumby, P. J. (2014). Global disparity in the ecological benefits of reducing carbon emissions for coral reefs. Nat. Clim. Chang. 4, 1090-1094. doi: 10.1038/nclimate2439 
Peters, G. P., Le Quér,é, C., Andrew, R. M., Canadell, J. G., Friedlingstein, P., Ilyina, T., et al. (2017). Towards real-time verification of CO2 emissions. Nat. Clim. Chang. 7, 848-850. doi: 10.1038/s41558-017-0013-9

Pörtner, H. O., Langenbuch, M., and Michaelidis, B. (2005). Synergistic effects of temperature extremes, hypoxia, and increases in $\mathrm{CO}_{2}$ on marine animals: from Earth history to global change. J. Geophys. Res. Ocean. 110:C09S10. doi: 10.1029/2004JC002561

Principe, P. P., Bradley, P., Yee, S. H., Fisher, W. S., Johnson, E. D., Allen, P., et al. (2012). Quantifying Coral Reef Ecosystem Services. Washighton, DC: U.S. Environmental Protection Agency.

Prouty, N. G., Storlazzi, C. D., Mccutcheon, A. L., and Jenson, J. W. (2014). Historic impact of watershed change and sedimentation to reefs along west-central Guam. Coral Reefs 33, 733-749. doi: 10.1007/s00338-014-1166-x

Rogers, A., Blanchard, J. L., and Mumby, P. J. (2014). Vulnerability of coral reef fisheries to a loss of structural complexity. Curr. Biol. 24, 1000-1005. doi: 10.1016/j.cub.2014.03.026

Ruttenberg, B. I., Hamilton, S. L., Walsh, S. M., Donovan, M. K., Friedlander, A., DeMartini, E., et al. (2011). Predator-induced demographic shifts in coral reef fish assemblages. PLoS ONE 6:e21062. doi: 10.1371/journal.pone.0021062

Selig, E. R., Casey, K. S., and Bruno, J. F. (2012). Temperature-driven coral decline: the role of marine protected areas. Glob. Chang. Biol. 18, 1561-1570. doi: 10.1111/j.1365-2486.2012.02658.x

Spalding, M., Burke, L., Wood, S. A., Ashpole, J., Hutchison, J., and zu Ermgassen, P. (2017). Mapping the global value and distribution of coral reef tourism. Mar. Policy 82, 104-113. doi: 10.1016/j.marpol.2017.05.014

Stamoulis, K. A., Poti, M., Delevaux, J. M. S., Donovan, M. K., Friedlander, A. M., and Kendall, M. S. (2016). “4. Fishes - Reef Fish,” in Marine Biogeographic Assessment of the Main Hawaiian Islands, eds. B. Costa and M. S. Kendall (Silver Spring, MD: OCS Study BOEM and NOAA Technical Memorandum NOS NCCOS 214), 156-196.

Thompson, A., and Dolman, A. (2010). Coral bleaching: one disturbance too many for near-shore reefs of the Great Barrier Reef. Coral Reefs 29, 637-648. doi: 10.1007/s00338-009-0562-0

Van Beukering, P. J. H., and Cesar, H. S. J. (2004). Ecological Economic modeling of coral reefs: evaluating tourist overuse at hanauma bay and algae blooms at the kihei coast. Pacific Sci. 58, 243-260. doi: 10.1353/psc.2004.0012

Van Hooidonk, R., Maynard, J. A., and Planes, S. (2013). Temporary refugia for coral reefs in a warming world. Nat. Clim. Chang. 3, 508-511. doi: $10.1038 /$ nclimate 1829

Van Hooidonk, R. J., Maynard, J., Tamelander, J., Gove, J., Ahmadia, G., Raymundo, L., et al. (2016). Local-scale projections of coral reef futures and implications of the paris agreement. Sci. Rep. 6:39666. doi: 10.1038/srep39666

Wainger, L., and Boyd, J. (2009). "Valuing ecosystem services," in Ecosystem-Based Management for the Oceans, eds K. McLeod and H. Leslie (Washington, DC: Island Press), 99-114.
Wedding, L. M., Lecky, J. H., Gove, J., Walecka, H. R., Donovan, M. K., Williams, G. J., et al. (2017). Advancing the integration of spatial data to map human and natural drivers on coral reefs. PLOS ONE 13:e0189792. doi: 10.1371/journal.pone.0189792

Weijerman, M., Fulton, E. A., and Brainard, R. E. (2016). Management strategy evaluation applied to coral reef ecosystems in support of ecosystembased management. PLoS ONE 11:e0152577. doi: 10.1371/journal.pone.01 52577

Weijerman, M., Fulton, E. A., Kaplan, I. C., Gorton, R., Leemans, R., Mooij, W. M., et al. (2015). An integrated coral reef ecosystem model to support resource management under a changing climate. PLOS ONE 10:e0144165. doi: 10.1371/journal.pone.0144165

Williams, I. D., Baum, J. K., Heenan, A., Hanson, K. M., Nadon, M. O., and Brainard, R. E. (2015). Human, oceanographic and habitat drivers of central and western Pacific coral reef fish assemblages. PLoS ONE 10:e0120516. doi: 10.1371/journal.pone.0120516

Williams, I. D., Richards, B. M., Sandin, S. A., Baum, J. K., Schroeder, R. E., Nadon, M. O., et al. (2011). Differences in reef fish assemblages between populated and remote reefs spanning multiple archipelagos across the central and western Pacific. J. Mar. Biol. 2011:826234. doi: 10.1155/2011/ 826234

Williams, I. D., Walsh, W. J., Schroeder, R. E., Friedlander, A. M., Richards, B. L., and Stamoulis, K. A. (2008). Assessing the importance of fishing impacts on Hawaiian coral reef fish assemblages along regional-scale human population gradients. Environ. Conserv. 35, 261-272. doi: 10.1017/S03768929080 04876

Wren, J. L. K., and Kobayashi, D. R. (2016). Exploration of the "larval pool": development and ground-truthing of a larval transport model off leeward Hawai'i. PeerJ. 4:e1636. doi: 10.7717/peerj.1636

Yee, S. H., Dittmar, J. A., and Oliver, L. M. (2014). Comparison of methods for quantifying reef ecosystem services: a case study mapping services for St. Croix, USVI. Ecosyst. Serv. 8, 1-15. doi: 10.1016/j.ecoser.2014. 01.001

Conflict of Interest Statement: The authors declare that the research was conducted in the absence of any commercial or financial relationships that could be construed as a potential conflict of interest.

Copyright (c) 2018 Weijerman, Veazey, Yee, Vaché, Delevaux, Donovan, Falinski, Lecky and Oleson. This is an open-access article distributed under the terms of the Creative Commons Attribution License (CC BY). The use, distribution or reproduction in other forums is permitted, provided the original author(s) and the copyright owner(s) are credited and that the original publication in this journal is cited, in accordance with accepted academic practice. No use, distribution or reproduction is permitted which does not comply with these terms. 